\title{
Women's Knowledge and Experience of Abnormal Vaginal Discharge Living in Estates in Colombo District, Sri Lanka
}

\author{
Mudiyanselage Prasanthi Sumudrika Ilankoon ${ }^{1^{*}}$, Christine Sampatha Evangeline Goonewardena ${ }^{2}$, Rukshan \\ Cleophas Fernandopulle ${ }^{3}$, Poruthotage Pradeep Rasika Perera ${ }^{4}$
}

\begin{abstract}
Objectives: Awareness about the causes for excessive vaginal discharge is very important to detect pathological entities from physiological forms in early stages to prevent associated complications. This study was aimed to describe knowledge and experience related to vaginal discharge among females aged 18 to 49 years living in estate communities in the Colombo District, Sri Lanka. Materials and Methods: This was a community based cross-sectional study of 550 females using an interviewer-administered questionnaire. Both descriptive and chi square analysis were used for data analysis.

Results: Nearly $78 \%$ of the participants were Tamil $(n=428)$ and the mean age was $33.8($ SD: \pm 8.15$)$ years. For the knowledge on vaginal discharge, $98.5 \%$ had obtained $<50 \%$ and only $8(1.5 \%)$ had a score between $50 \%-75 \%$. A significant difference in knowledge score was observed with respect to the family type $(P=0.031)$. Main cause for excessive vaginal discharge was high body temperature (64.7\%). Fifty-four percent reported that they have experienced excessive vaginal discharge and only $30 \%$ had sought medical advice $(\mathrm{n}=165)$. Those who had other accompanying symptoms such as itchiness and scratching, lower abdominal pain, burning sensation and pain during intercourse had sought treatment from a general practitioner $(P<0.05)$. There was poor treatment seeking behavior among the females aged below 35 years $(P=0.027)$. Main reason for not seeking medical advice was feeling uncomfortable in discussing the issue with a male doctor $(87.8 \%)$.

Conclusion: Majority of the study participants had poor knowledge on vaginal discharge displaying the inability to differentiate normal from abnormal. It is recommended to increase awareness to improve health seeking behaviour towards excessive vaginal discharge.

Keywords: Health, Knowledge, Vaginal discharge
\end{abstract}

\section{Introduction}

Being a healthy woman is important to have good reproductive health and to have a healthy baby. Reproductive health problems constitute the leading cause of ill health in women of reproductive age group worldwide especially in developing countries $(1,2)$. Ignoring these preventable and treatable conditions can lead to distressful situations among many women.

An initial symptom of most reproductive tract diseases is abnormal vaginal discharge, which can be physiological or pathological (3). Pathological causes for vaginal discharge are due to genital tract malignancy, fistulae, allergic reactions, atrophic vaginitis (menopausal) and reproductive tract infections (4). The most common causes of vaginal discharge are physiological causes, bacterial vaginosis, and candidiasis (5). Reproductive tract infections can be a threat to women's health and lead to severe consequences such as infertility, ectopic pregnancy, chronic pelvic pain, abortion and an increased risk of HIV transmission $(6,7)$.
Women living in the estate sector of Sri Lanka are considered as a socially marginalized community and are vulnerable to many unhealthy practices and lifestyles. They have poor health and education outcomes relative to the rest of the country (8). They live in congested and unsanitary housing with little access to social services due to the isolated nature of the locations of the estates and linguistic differences (9). The pattern and the frequency of reproductive tract infections depend heavily on the sociocultural setting in which the women live (10) and has shown an increasing prevalence among the lower socioeconomic class (11). In contrast, women with higher standards of living show significantly lower levels of prevalence of reproductive health problems due to better nutrition, sanitation and hygienic conditions (12). Further, women living in rural areas have a higher chance of getting diseases associated with vaginal discharge due to lack of knowledge on diseases related to reproductive tract and their symptoms (13). Furthermore, these infections may be due to lack of hygiene or adoption of risky behaviors 
such as not using condoms or having multiple sexual partners (14). Women from low educational backgrounds seem to be silent regarding their reproductive and sexual health issues (12) than women from urban communities.

Health education for women of reproductive age regarding infection prevention, proper use of health services and self-care methods is essential in reducing disease transmission in many societies (15). It is important to develop health education interventions according to the educational needs of the relevant community. Hence, this study aimed to assess the level of knowledge and experiences of excessive vaginal discharge among women living in estate communities in order to design a health education intervention.

\section{Materials and Methods}

This community based descriptive cross-sectional study was conducted in estates in the Colombo District, Sri Lanka from August to December 2015. Females aged 18-49 years living in the estate sector for more than 6 months prior to the study were included. Females who were cognitively impaired at the time of the study were excluded.

Expected proportion of females who had good level of knowledge on vaginal discharge was taken as 0.5 and the sample thus required was estimated at 384. Accounting for the multistage cluster sampling technique and for non-response, the final sample required was 550 females. Sample was distributed among the estates according to the female population among each estate received from the Plantation Human Development Trust (PHDT), with proportional allocation. Number of clusters was taken as 30 according to the World Health Organization (WHO) guidelines (16) and decided cluster size from each estate.

Data were collected using a self-developed, validated, pretested Interviewer Administered Questionnaire (IAQ). The judgmental validity of the instrument was assured by a panel of experts in the field of reproductive health. IAQ consisted of socio-demographic characteristics of the females, close and open ended questions to assess knowledge and practices related to vaginal discharge. In assessing knowledge each correct answer was given a score of 1 and an incorrect response 0 . Knowledge was specified as adequate knowledge - $>75 \%$, moderate knowledge between $50 \%-75 \%$ and inadequate knowledge $<50 \%$ (17).

Data were coded and double entered in to SPSS software version 16. Descriptive statistics was applied to obtain percentage and means and relevant inferential statistics was performed. Chi squared test was carried out to determine the association between the knowledge score and other factors. A P value of 0.05 or less was considered significant.

\section{Results}

Socio-Demographic Characteristics

Five hundred fifty females participated in this study. Majority of them $(78 \%)$ were Tamils $(n=428)$ and the age of females ranged from 18 to 49 years and the mean age was 33.8 (SD: \pm 8.15 ) years. The majority has had primary education or less $(n=332,60.4 \%)$ and were employed $(60.4 \%)$. More than $88 \%$ were married $(n=487)$ and nearly half of them had a nuclear type family (53.1\%) with the mean average monthly income of Rs. 8484.55 (US\$58). The mean duration of living in estate sector was $21(\mathrm{SD} \pm 13.60)$ years (Table 1$)$. The main sources of information regarding the topic for the present community were friends $(n=309,56.2 \%)$, relatives $(n=228,41.5 \%)$, general practitioner $(n=81,14.7 \%)$, clinics $(n=78,14.1 \%)$ and television $(n=69,12.5 \%)$.

\section{Knowledge Regarding Vaginal Discharge}

Majority of the study participants stated that any type of vaginal discharge is normal $(n=405,73.6 \%)$. The colour of the vaginal discharge was mentioned as clear $(12.5 \%$, $\mathrm{n}=69)$, white $(80.4 \%, \mathrm{n}=442)$ or yellow $(4.2 \%, \mathrm{n}=23)$. The consistency of the normal vaginal discharge was identified as thin $(n=313,56.9 \%)$, thick white $(n=147$, $26.7 \%$ ) or mucoid $(n=90,16.4 \%)$. Ninety four percent of the participants agreed that the odor of the normal vaginal discharge is non-offensive $(n=515)$.

Further, majority of the participants (88.0\%) agreed that "a clear, non-offensive discharge that varies with the menstrualcycle is a normal physiological secretion" and 77\% agreed that "women aged between 15-49 years have a normal physiological vaginal secretion." Majority of them $(60.2 \%)$ were not aware that "the most common cause of vaginal discharge is sexually transmitted disease (STD)" (Table 2).

Awareness of Sexually Transmitted Diseases and Causes of Excessive Vaginal Discharge

Responding to the question on STDs, nearly $59 \%$ of the participants $(n=234)$ mentioned HIV as a STD. Very few of them mentioned other STDs such as gonorrhea, syphilis and herpes. High body temperature was mentioned as a main cause for excessive vaginal discharge by $64.7 \%$ of the study participants (Table 3 ).

Overall Knowledge Score on Vaginal Discharge and Sexually Transmitted Diseases

The mean knowledge score regarding overall knowledge on vaginal discharge and STDs was 27.01 (SD: \pm 8.61 ) out of the maximum score of $100,98.5 \%$ of participants had obtained $<50 \%$ and $1.5 \%$ had obtained a score between $50 \%-75 \%$. A significant statistical difference was noticed between knowledge score and the family type of the participants $(P=0.031$; Table 1$)$.

\section{Health Seeking Behaviours}

Fifty-four percent of the participants reported that abnormal vaginal discharge has been a concern for them $(n=297$, Table 1). From those who had experience excessive vaginal discharge, only $30 \%$ had taken treatment from a general practitioner $(n=165)$ and others have taken other steps or have ignored the symptom. Sixty-six participants, who had consulted a general practitioner, 
Table 1. Distribution of Socio-Demographic Characteristics and Knowledge Score $(N=550)$

\begin{tabular}{|c|c|c|c|c|c|}
\hline \multirow[b]{2}{*}{ Characteristics } & & \multicolumn{3}{|c|}{ Knowledge Score (n, \%) } & \multirow[b]{2}{*}{$P$ Value } \\
\hline & & $\begin{array}{l}\text { Moderate } \\
\text { (n, \%) }\end{array}$ & $\begin{array}{c}\text { Inadequate } \\
\text { (n, \%) }\end{array}$ & $\begin{array}{l}\text { Total } \\
\text { (n, \%) }\end{array}$ & \\
\hline \multirow{3}{*}{ Ethnicity } & Sinhalese & $1(12.5)$ & $109(20.1)$ & $110(20.0)$ & \multirow{3}{*}{0.123} \\
\hline & Tamils & $6(75.0)$ & 422 (77.9) & $428(77.8)$ & \\
\hline & Others & $1(12.5)$ & $11(2.0)$ & $12(2.2)$ & \\
\hline \multirow{4}{*}{ Religion } & Buddhist & $1(12.5)$ & $110(20.3)$ & $111(20.2)$ & \multirow{4}{*}{0.148} \\
\hline & Hindu & $5(62.5)$ & $324(59.8)$ & $329(59.8)$ & \\
\hline & Christian & $0(0.0)$ & $73(13.5)$ & $73(13.5)$ & \\
\hline & Others & $2(25.0)$ & $35(6.5)$ & $37(6.7)$ & \\
\hline \multirow{2}{*}{ Age categories } & Below 35 years & $4(50.0)$ & $315(58.1)$ & $319(58.0)$ & \multirow{2}{*}{0.664} \\
\hline & Above 36 years & $4(50.0)$ & 227 (41.9) & $231(42.0)$ & \\
\hline \multirow{2}{*}{ Highest educational level } & Below primary & $4(50.0)$ & $328(60.5)$ & $332(60.4)$ & \multirow{2}{*}{0.546} \\
\hline & Above primary & $4(50.0)$ & $214(39.5)$ & $218(39.6)$ & \\
\hline \multirow{2}{*}{ Employment status } & Employed & $5(62.5)$ & $327(60.3)$ & $332(60.4)$ & \multirow{2}{*}{0.901} \\
\hline & Unemployed & $3(37.5)$ & 215 (39.7) & $218(39.6)$ & \\
\hline \multirow{3}{*}{ Marital Status } & Married & $8(100.0)$ & $479(88.4)$ & $487(88.5)$ & \multirow{3}{*}{0.592} \\
\hline & Single & $0(0.0)$ & 43 (7.9) & $43(7.8)$ & \\
\hline & Separate/widow & $0(0.0)$ & $20(3.7)$ & $20(3.6)$ & \\
\hline \multirow{3}{*}{ Family type } & Nuclear & $2(25.0)$ & $290(53.5)$ & $292(53.1)$ & \multirow{3}{*}{0.031} \\
\hline & Extended & $3(37.5)$ & $198(36.5)$ & $201(36.5)$ & \\
\hline & Joint & $3(37.5)$ & $54(10.0)$ & $57(10.4)$ & \\
\hline \multirow{2}{*}{ Experience with abnormal vaginal discharge } & Yes & $4(50.0)$ & $293(54.1)$ & $297(54.0)$ & \multirow[t]{2}{*}{0.819} \\
\hline & No & $4(50.0)$ & 249 (45.9) & $253(46.0)$ & \\
\hline
\end{tabular}

Table 2. Knowledge related to vaginal discharge

\begin{tabular}{|c|c|c|c|}
\hline Responses & $\begin{array}{c}\text { True } \\
(n, \%)\end{array}$ & $\begin{array}{l}\text { False } \\
(\mathrm{n}, \%)\end{array}$ & $\begin{array}{c}\text { Don't Know } \\
(n, \%)\end{array}$ \\
\hline A clear, non-offensive discharge that varies with the menstrual cycle is a normal physiological secretion. & $440(88.0)$ & $32(5.8)$ & $78(14.2)$ \\
\hline Vaginal secretions vary with menstrual cycle. & $352(64.0)$ & $67(12.2)$ & $131(23.8)$ \\
\hline The most common cause of vaginal discharge is STDs. & $130(23.6)$ & $89(16.2)$ & $331(60.2)$ \\
\hline Women aged between $15-49$ years have a normal physiological vaginal secretion & $424(77.1)$ & $21(3.8)$ & $105(19.1)$ \\
\hline White or colored vaginal discharge may be a sign of reproductive tract infections. & $315(57.3)$ & $34(6.2)$ & $201(36.5)$ \\
\hline Candida infection is a sexually transmitted infection. & $43(7.8)$ & $56(10.2)$ & $451(82)$ \\
\hline
\end{tabular}

have done it within a month of appearance of excessive discharge.

The majority $(\mathrm{n}=379,68.9 \%)$ mentioned that consultation with a general practitioner is the common health seeking behavior of other known females. The majority (73.8\%) have sought medical advice when the condition has got worse. Most of the participants (87.8\%) stated "feeling uncomfortable in discussing with a male doctor" is the reason for not seeking medical advice for excessive vaginal discharge (Table 4).

Treatment Seeking From a General Practitioner and its Associated Factors

Most of the participants who had lower education level have sought treatment for excessive vaginal discharge. Majority of the married women sought treatment for excessive vaginal discharge compared to others. Treatment seeking behavior from a general practitioner was not statistically significant with the educational level $(P=0.223)$, religion $(P=0.075)$, ethnicity $(P=0.328)$, employment status $(P=0.648)$ and marital status $(P=0.509)$. But there was a statistically significant association between treatment seeking behaviors and age of the participants $(P=0.027$; Table 5).

Other symptoms experienced with abnormal vaginal discharge

Other symptoms experienced with abnormal vaginal discharge were itchiness and scratching $(\mathrm{n}=135,24.5 \%)$, lower abdominal pain $(\mathrm{n}=79,14.4 \%)$, burning sensation $(\mathrm{n}=62,11.3 \%)$, pain during intercourse $(\mathrm{n}=13,2.4 \%)$ and backache $(\mathrm{n}=12,2.2 \%)$. The accompanying symptoms with abnormal vaginal discharge such as itchiness and scratching $(P=0.000)$, lower abdominal pain $(P=0.000)$, burning sensation $(P=0.000)$ and pain during intercourse $(P=0.012)$ had a statistically significant association with seeking treatment from a general practitioner (Table 6).

\section{Discussion}

This study was done with the objective of assessing knowledge and experience related to vaginal discharge among females aged 18 to 49 years. The study population 
Table 3. Awareness of Sexually Transmitted Diseases and Causes of Excessive Vaginal Discharge

\begin{tabular}{lc}
\hline Responses & No (\%) \\
\hline Awareness of sexually transmitted diseases & $234(58.9)$ \\
AIDS & $17(3.1)$ \\
Gonorrhea & $5(0.9)$ \\
Syphilis & $4(0.7)$ \\
Herpes & \\
Causes for excessive vaginal discharge & \\
High body temperature & $356(64.7)$ \\
Vitamin deficiency & $182(33.1)$ \\
Heaty food & $131(23.8)$ \\
Bone melting & $63(11.5)$ \\
Infections & $57(10.4)$ \\
Pregnancy & $54(9.8)$ \\
Poor personal hygiene & $39(7.1)$ \\
Body weakness & $35(6.4)$ \\
Stress & $20(3.6)$ \\
Sexually transmitted Infections & $14(2.5)$ \\
Family planning methods & $13(2.4)$ \\
Melting veins & $12(2.2)$ \\
Cancer & $11(2.2)$ \\
Heavy working & 10 \\
\hline
\end{tabular}

was a low-income estate community where women do not generally use health services and mainly work on estates fulltime. Study sample mainly consisted of an ethnic Tamil population and have been educated only up to primary education level or below. It is a proven fact that educated women report significantly lower levels of prevalence of reproductive morbidity compared to illiterate women as they have more exposure to print and electronic media (12).

The main sources of information regarding vaginal discharge were friends and relatives which indicate thelower access to other sources in the present study population. Similar results have been reported in another study where family members and friends have been identified as the main source of information on vaginal discharge $(18,19)$. In contrast, a study done in Nigeria reported that health professionals as a source of information than friends and relatives in some communities (20).

Women's education seems to be an important factor which helps in prevention of complications of reproductive health disease (12). The high body temperature followed by vitamin deficiency and body weakness were stated by participants as the main causes for excessive vaginal discharge and very few mentioned that infections, STDs, cancer and pregnancy as causes for excessive discharge. Similarly a study conducted in an urban slum community in Dhaka, Bangladesh found that body weakness being mentioned as a cause of abnormal vaginal discharge (21). It was mentioned in other studies that internal gynecological problems (22), body weakness $(22,23)$, melting bones (24), illness (24) and infertility (24) as causes for vaginal discharge.

Further, in our study majority of the participants had inadequate level of knowledge on vaginal discharge. The women from estate community mainly provide estate labour which limits them from exposure to awareness programmes and other outside health services. The structure of the living environment, lack of access for sources of information and the poor educational level can lead to many unhealthy practices among this community.

Table 4. Health Seeking Behaviours Related to Vaginal Discharge

\begin{tabular}{|c|c|c|}
\hline & Responses $^{a}$ & No. (\%) \\
\hline \multirow{5}{*}{$\begin{array}{l}\text { Health seeking behaviours of } \\
\text { the study participants }\end{array}$} & Consulted a general practitioner & $165(30)$ \\
\hline & Discuss with friend or relatives & $46(8.4)$ \\
\hline & Used home remedies & $13(2.4)$ \\
\hline & Discuss with PHM & $11(2)$ \\
\hline & Consulted Ayurvedic Doctor & $7(1.3)$ \\
\hline \multirow{4}{*}{$\begin{array}{l}\text { Health seeking behaviours of } \\
\text { known others }\end{array}$} & Consulted a general practitioner & $379(68.9)$ \\
\hline & Consulted Ayurvedic Doctor & $42(7.6)$ \\
\hline & Used home remedies & $40(7.3)$ \\
\hline & Use over the counter products & $12(2.2)$ \\
\hline \multirow{5}{*}{$\begin{array}{l}\text { The reasons for seeking } \\
\text { medical advice at the end }\end{array}$} & The condition has got worse & $406(73.8)$ \\
\hline & Fear of serious disease & $316(57.5)$ \\
\hline & Vaginal discharge is intolerable & $261(47.5)$ \\
\hline & Fear of sexually transmitted infection & $70(12.7)$ \\
\hline & Previous good experience with medical treatments & $53(9.6)$ \\
\hline \multirow{7}{*}{$\begin{array}{l}\text { The reasons for females not } \\
\text { to seek medical advice }\end{array}$} & Feeling uncomfortable in discussing with male doctor & $483(87.8)$ \\
\hline & Less knowledgeable about vaginal discharge & $253(46)$ \\
\hline & Considering vaginal discharge as normal & $179(32.5)$ \\
\hline & Afraid of internal examination because of being unmarried & $142(25.8)$ \\
\hline & Busy with household activities and ignore it & $129(23.5)$ \\
\hline & Cultural view of vaginal discharge & $56(10.2)$ \\
\hline & It relieves with the home remedies & $45(8.2)$ \\
\hline
\end{tabular}

${ }^{a}$ Multiple responses were allowed. 
Table 5. Treatment Seeking From a General Practitioner and Associated Factors

\begin{tabular}{|c|c|c|c|c|c|}
\hline \multirow{2}{*}{ Characteristics } & & \multicolumn{3}{|c|}{ Consulted a General Practitioner } & \multirow{2}{*}{$P$ Value } \\
\hline & & Yes (n, \%) & No $(n, \%)$ & Total (n, \%) & \\
\hline \multirow{2}{*}{ Educational levels } & Below primary education & $106(64.2)$ & $226(58.7)$ & $332(60.4)$ & \multirow{2}{*}{0.223} \\
\hline & Above primary education & $59(35.8)$ & $159(41.3)$ & $218(39.6)$ & \\
\hline \multirow{4}{*}{ Religion } & Buddhist & $39(22.6)$ & $72(18.7)$ & $111(20.2)$ & \multirow{4}{*}{0.075} \\
\hline & Hindu & $96(58.2)$ & $233(60.5)$ & $329(59.8)$ & \\
\hline & Christian & $25(15.2)$ & $48(12.5)$ & $73(13.3)$ & \\
\hline & Others & $5(3)$ & $32(8.3)$ & $37(6.7)$ & \\
\hline \multirow{3}{*}{ Ethnicity } & Sinhalese & $38(23)$ & $72(18.7)$ & $110(20)$ & \multirow{3}{*}{0.328} \\
\hline & Tamil & $125(75.8)$ & $303(78.7)$ & $428(77.8)$ & \\
\hline & Others & $2(1.2)$ & $10(2.6)$ & $12(2.2)$ & \\
\hline \multirow{2}{*}{ Employment status } & Employed & $102(61.8)$ & $230(59.7)$ & $332(60.4)$ & \multirow{2}{*}{0.648} \\
\hline & Unemployed & $63(38.2)$ & $155(40.3)$ & $218(39.6)$ & \\
\hline \multirow{3}{*}{ Marital Status } & Married & $146(88.5)$ & $341(88.6)$ & $487(88.5)$ & \multirow{3}{*}{0.509} \\
\hline & Single & $11(6.7)$ & $32(8.3)$ & $43(7.8)$ & \\
\hline & Separate/widow & $8(4.8)$ & $12(3.1)$ & $20(3.6)$ & \\
\hline \multirow{3}{*}{ Family type } & Nuclear & $96(58.2)$ & $196(50.9)$ & $292(53.1)$ & \multirow{3}{*}{0.284} \\
\hline & Extended & $53(32.1)$ & $148(38.4)$ & $201(36.5)$ & \\
\hline & Joint & $16(9.7)$ & $41(10.6)$ & $57(10.4)$ & \\
\hline \multirow{2}{*}{ Age categories } & Below 35 years & 84 (50.9) & $235(61.0)$ & $319(58.0)$ & \multirow{2}{*}{0.027} \\
\hline & Above 36 years & 81 (49.1) & $150(39.0)$ & $231(42.0)$ & \\
\hline
\end{tabular}

Table 6. Other Symptoms Experienced With Abnormal Vaginal Discharge

\begin{tabular}{|c|c|c|c|c|}
\hline \multirow{2}{*}{ Accompanying Symptoms } & \multicolumn{3}{|c|}{ Consulted a General Practitioner } & \multirow{2}{*}{$P$ Value } \\
\hline & Yes (n, \%) & No (n, \%) & Total (n, \%) & \\
\hline Burning sensation & $51(30.9)$ & $11(2.9)$ & $62(11.3)$ & 0.000 \\
\hline Lower abdominal pain & $57(34.5)$ & $22(5.7)$ & $79(14.4)$ & 0.000 \\
\hline Itchiness and scratching & $85(51.5)$ & $50(13)$ & $135(24.5)$ & 0.000 \\
\hline Pain during intercourse & $8(4.8)$ & $5(1.3)$ & $13(2.4)$ & 0.012 \\
\hline
\end{tabular}

Similarly, studies done in Vietnam and Istanbul reported that identification of vaginal discharge as a symptom associated with suspected reproductive tract infections was poor among women $(25,26)$. Further, another study revealed that most of the participants had no prior factual knowledge about vaginal discharge and its nature (24). Overall knowledge of the respondents about the symptoms of reproductive tract infections was poor in another research and nearly half agreed that vaginal discharge as a symptom of reproductive tract infections (20). In the present study, majority mentioned HIV as a STD and very few of them mentioned other STDs such as gonorrhea, syphilis and herpes which indicate lack of awareness on sexually transmitted infections. In contrast, a study done by Payne et al showed that African-American women had basic knowledge of associated factors of bacterial vaginosis, linking occurrence to sexual activity, tub bathing and douching (27). Educational level, religion and ethnicity were not significantly associated with the knowledge levels regarding vaginal discharge in the present study.

More than half of the study participants reported experiencing excessive vaginal discharge in the present study. It was found that $24.6 \%$ had presented with vaginal discharge in a similar community (22). Oliveira et al. stated that out of women who complained about abnormal vaginal discharge, less than $25 \%$ had pathological discharge (10). In contrast, another study stated that from $6 \%$ who were not reporting excessive vaginal discharge, the physician found moderate or substantial discharge (28). These findings indicate the possibility of untreated reproductive tract infection among women in reproductive age group due to inability of differentiating pathological and physiological vaginal discharge. Zurayk et al further emphasized that discharge itself is not a good predictor but highlighted the necessity to elicit further information on characteristics of the discharge and the women's perception of its abnormality (28). But, in contrast, it is stated that vaginal discharge is a good predictor to diagnose reproductive tract infections or STDs (20). Therefore, the ability to differentiate abnormal vaginal discharge from normal and seeking medical advice where necessary would be imperative to early diagnosis and treatment of reproductive tract infections and other reproductive health problems.

In a study conducted in poor urban communities in Mumbai, India it was found that majority of women believe that vaginal discharge is an unavoidable and a natural consequence of womanhood (23). Even in the present study among women living in the estate community, women delayed treatment thinking that any type of vaginal discharge is normal. Further, these women 
have not taken treatment from a medical practitioner due to feeling uncomfortable in discussing the condition with a male doctor. Similar results were reported from other studies where women were reluctant to seek treatment because of cultural inhibitions and feeling ashamed in consulting a male doctor $(29,30)$. In our study cultural views on vaginal discharge was mentioned by a few as a reason for females not seeking medical advice. However, Rashid reported that women are worried that people would mix up any vaginal discharge with discharge that is caused by STDs leading to stigmatization (21). In contrast, African-American women in United States reported that most women consulted medical advice within one week of onset of symptoms and especially, over half of these women were comfortable in consulting male health care providers (27).

Majority of the study participants of the present study mentioned that they have sought treatment at the end because the condition got worse or fear of serious disease consequences. Treatment seeking behavior was not significantly associated with the educational level, religion, ethnicity, employment status and marital status in the present study. However, older women were found to have better health seeking behavior compared to younger women. Similar findings were reported by Gulati et al in which older women were more likely than younger women to seek treatment for reproductive tract infections (12). Another study reported that the prevalence of STDs, particularly of HPV, gonorrhea and chlamydia in adolescents was higher among younger age group when compared to older age groups (10) which indicates the importance of interventions to improve health seeking behaviours in the younger age group.

It was significant that having other accompanying symptoms such as itchiness and scratching, lower abdominal pain, burning sensation and pain during intercourse with abnormal vaginal discharge were positive predictors to seek medical advice in this community. Similarly, having other symptoms with pathological vaginal discharge has been found to be a motivating factor to seek treatment in other populations as well $(12,20)$.

\section{Conclusion}

Reproductive health problems affect millions of women around the world and there are many misconceptions and myths related to these morbidities. Vaginal discharge is a common complaint among women at reproductive age group and it is one of most common symptoms of gynecological disorders. Around 54\% of females aged 18-49 in estate communities were found to be suffering from vaginal discharge with accompanying symptoms such as itchiness and scratching, burning sensation, lower abdominal pain and pain during intercourse. It was concluded that among women suffering from excessive vaginal discharge, majority (70\%) did not seek any advice or treatment. The level of knowledge was inadequate among majority (98.5\%) of the study participants indicating the need for enhancing awareness regarding the importance of seeking medical advice.

According to the study of Ebrahimi Tavani et al, "consultation and education for efficient preventive healthy behaviors is one of the hottest topics in sexual and reproductive health" (7). Health education should be directed towards younger women to empower them to recognize abnormal vaginal discharge as early as possible. Furthermore, it is important to educate this community on common gynecological disorders and associated serious health outcomes considering their socio-economic background. Improving knowledge and awareness play a significant role in changing individuals' attitude, behavior and practice (7). Thus, this effort should be targeted to improve this socially marginalized community's awareness regarding causes of abnormal vaginal discharge specially focusing on reproductive tract infections which can be prevented, managed in such a way as to prevent recurrence and cross transmission.

\section{Ethical Issues}

Ethical clearance was obtained from the Ethics Review Committee, Faculty of Medical Sciences, University of Sri Jayewardenepura, Sri Lanka. Recruitment of all participants for the study was strictly voluntarily. Informed written consent from participants was obtained prior to the enrolment to the study. The procedures followed were in accordance with the ethical standards of the Declaration of Helsinki of the World Medical Association.

\section{Conflict of Interests}

Authors declare that there is no conflict of interest.

\section{Financial Support}

The authors appreciate the institutional research grant (Grant No: ASP/06/RE/MED/2013/31) of University of Sri Jayewardenepura, Sri Lanka for financial support.

\section{Acknowledgments}

The authors thank all the participants for their support and the cooperation of staff of each estate.

\section{References}

1. United Nation Population Fund. Improving reproductive health: Population issues. http://www.unfpa.org/rh/index. htm.

2. Abraham A, Varghese S, Satheesh M, Vijayakumar K, Gopakumar S, Mendez A. Pattern of gynecological morbidity, its factors and health seeking behavior among reproductive age group women in a rural community of Thiruvananthapuram district, South Kerala. Indian J Community Health. 2014;26(3):230-237.

3. Patil SP, Thakur S. A study of abnormal vaginal discharge among married women of reproductive age group at urban health centre group attending urban health centre. National J Integ Res Med. 2016;7(2):66-72.

4. FSRH and BASHH Guidance Clinical effectiveness UnitManagement of Vaginal Discharge in Non-Genitourinary Medicine Settings. February 2012.

5. Fahami R. Abnormal vaginal discharge. BMJ. 2013;347:1-3. doi: 10.1136/bmj.f4975. 
6. World Health Organization. Development of a SelfLearning Module on Management of Sexually Transmitted Infections for Private Practitioners in WHO South-East Asia Region. Report of an Informal Consultation Colombo, Sri Lanka; 2006: 29-30.

7. Ebrahimi Tavani M, Ghofranipour F, Hajizadeh E, Abedini M. Assessment of educational needs among women of reproductive age with common genital tract infections (Vaginitis): The first step for developing a self-care educational package. Int J Womens Health Reprod Sci. 2015;3(4):201-207. doi:10.15296/ijwhr.2015.42.

8. Department of Census and Statistics. The Sri Lankan Women Partner in Progress; 2014.

9. United Nations Development Programme Sri Lanka. Sri Lanka Human Development Report 2012, Bridging Regional Disparities for Human Development. 2012.

10. Oliveira FA, Pfleger V, Lang K, Heukelbach J, Miralles I, Fraga F, et al. Sexually transmitted infections, bacterial vaginosis, and candidiasis in women of reproductive age in rural Northeast Brazil: a population-based study. Mem Inst Oswaldo Cruz. 2007;102(6):751-756. doi:10.1590/S007402762007000600015 .

11. Balamurugan SS. Bendigeri ND. Community-based study of reproductive tract Infections among women of the reproductive age group in the urban health training centre area in Hubli, Karnataka. Indian J Community Med 2012;37(1):34-38. doi:10.4103/0970-0218.94020.

12. Gulati SC, Chaurasia AR, Singh RM. Women'S reproductive morbidity and treatment-seeking behaviour in India. Asian Popul Stud. 2009;5(1):61-84. doi:10.1080/17441730902790131.

13. Adıbelli D, Kılınç NO, Akpak YK, Kılıç D. Genital hygiene behaviors and associated factors in women living in rural areas of Turkey. Elect Med J. 2014;2(3):210-214. doi: 10.18035/emj.v2i3.163.

14. Karou SD, Djigma F, Sagna T, Nadembega C, Zeba M, Kabre A, et al. Antimicrobial resistance of abnormal vaginal discharges microorganisms in Ouagadougou, Burkina Faso. Asian Pac J Trop Biomed. 2012;2(4):294-297. doi:10.1016/ S2221-1691(12)60025-2.

15. World Health Organization. Sexually Transmitted and Other Reproductive Tract Infections Integrating STI/ RTI Care for Reproductive Health: A Guide to Essential Practice. Geneva: WHO; 2005.

16. Henderson RH, Sundaresan T. Cluster sampling to assess immunization coverage: a review of experience with a simplified sampling method. Bull World Health Organ. 1982;60(2):253-260.

17. Kisokanth G, Prathapan G, Indrakumar J, Joseph J. Patients with diabetes mellitus in a tertiary care hospital; their knowledge on disease, treatments and complications. Int J Curr Res. 2014; 6(7):7487-7492.

18. Karasz A, Anderson M. The vaginitis monologues: Women's experiences of vaginal complaints in a primary care setting.
Soc Sci Med. 2003;56(5):1013-1021. doi:10.1016/S02779536(02)00092-8.

19. Rizvi N, Luby S. Vaginal discharge: perceptions and health seeking behavior among Nepalese women. J Pak Med Assoc. 2004;54(12):620-624.

20. Rabiu K, Adewunmi A, Akinlusi FM, Akinola OI. Female reproductive tract infections: understandings and care seeking behaviour among women of reproductive age in Lagos, Nigeria. BMC Womens Health. 2010;10:8. doi:10.1186/1472-6874-10-8.

21. Rashid SF. Durbolota (weakness), chinta rog (worry illness), and poverty: explanations of white discharge among married adolescent women in an urban slum in Dhaka, Bangladesh. Med Anthropol Q. 2007;21(1):108132. doi:10.1525/MAQ.2007.21.1.108.108.

22. Chaudhary V, Kumar R, Agrawal VK, Singh A, Narula $\mathrm{R}$, Sharma M. Prevalence and determinants of vaginal discharge among women of reproductive age group in tertiary care hospital of Northern India. Natl J Community Med. 2012;3(4):661-665.

23. Kostick KM, Schensul SL, Jadhav K, Singh R, Bavadekar A, Saggurti N. Treatment seeking, vaginal discharge and psychosocial distress among women in urban Mumbai. Cult Med Psychiatry. 2010;34(3):529-547. doi:10.1007/ s11013-010-9185-8.

24. Fatima H, Khan N. Perceptions of women reporting vaginal discharge at gynecology clinics in Lahore. Psychol Health 2013;28:209.

25. Nielsen A, Lan PT, Marrone G, Phuc HD, Chuc NTK, Stålsby Lundborg C. Reproductive tract infections in rural Vietnam, women's knowledge, and health-seeking behavior: A cross-sectional study. Health Care Women Int. 2016;37(4):392-411. doi:10.1080/07399332.2014.920021.

26. Onal AE, Onoglu N, Babaoglu AB, Ozer C, Gungor G. Some hygiene behaviours and genital infection complaints among 15-49 aged women in a Suburban area of Istanbul. Nob Med. 2011;7(2):96-100.

27. Payne SC, Cromer PR, Stanek MK, Palmer AA. Evidence of African-American women's frustrations with chronic recurrent bacterial vaginosis. J Am Acad Nurse Pract. 2010; 22(2):101-108. doi:10.1111/j.1745-7599.2009.00474.x.

28. Zurayk H, Khattab H, Younis N, Kamal O, el-Helw M. Comparing women's reports with medical diagnoses of reproductive morbidity conditions in rural Egypt. Stud Fam Plann. 1995;26(1):14-21.

29. Bhatti LI, Fikree FF. Health-seeking behavior of Karachi women with reproductive tract infections. Social Science Med 2002;54(1):105-117.

30. Malta M, Bastos F, Strathdee S, Cunnigham S, Pilotto J, Kerrigan D. Knowledge, perceived stigma, and care-seeking experiences for sexually transmitted infections: a qualitative study from the perspective of public clinic attendees in Rio de Janeiro, Brazil. BMC Public Health. 2007;7:18.

Copyright ( 2017 The Author (s); This is an open-access article distributed under the terms of the Creative Commons Attribution License (http://creativecommons.org/licenses/by/4.0), which permits unrestricted use, distribution, and reproduction in any medium, provided the original work is properly cited. 